\title{
Mammary tumors that become independent of the type I insulin-like growth factor receptor express elevated levels of platelet-derived growth factor receptors
}

\author{
Craig I Campbell and Roger A Moorehead ${ }^{*}$
}

\begin{abstract}
Background: Targeted therapies are becoming an essential part of breast cancer treatment and agents targeting the type I insulin-like growth factor receptor (IGF-IR) are currently being investigated in clinical trials. One of the limitations of targeted therapies is the development of resistant variants and these variants typically present with unique gene expression patterns and characteristics compared to the original tumor.

Results: MTB-IGFIR transgenic mice, with inducible overexpression of the IGF-IR were used to model mammary tumors that develop resistance to IGF-IR targeting agents. IGF-IR independent mammary tumors, previously shown to possess characteristics associated with EMT, were found to express elevated levels of PDGFR $\alpha$ and PDGFRß. Furthermore, these receptors were shown to be inversely expressed with the IGF-IR in this model. Using cell lines derived from IGF-IR-independent mammary tumors (from MTB-IGFIR mice), it was demonstrated that PDGFR $\alpha$ and to a lesser extent PDGFR $\beta$ was important for cell migration and invasion as RNAi knockdown of PDGFR $\alpha$ alone or PDGFR $\alpha$ and PDGFR $\beta$ in combination, significantly decreased tumor cell migration in Boyden chamber assays and suppressed cell migration in scratch wound assays. Somewhat surprisingly, concomitant knockdown of PDGFR $\alpha$ and PDGFR $\beta$ resulted in a modest increase in cell proliferation and a decrease in apoptosis.

Conclusion: During IGF-IR independence, PDGFRs are upregulated and function to enhance tumor cell motility. These results demonstrate a novel interaction between the IGF-IR and PDGFRs and highlight an important, therapeutically relevant pathway, for tumor cell migration and invasion.
\end{abstract}

Keywords: IGF-IR, PDGFR, Breast cancer, Migration, Resistance

\section{Background}

Targeting receptor tyrosine kinases (RTKs) for the treatment of breast cancer has emerged as a promising direction for the management of this disease. However, a major drawback of this line of treatment is the propensity of tumors to acquire resistance. For example, a number of mechanisms have been identified as mediators of resistance to the commonly used Her2-directed therapeutic trastuzumab (reviewed in [1]). Therefore, a powerful tool for overcoming this shortcoming and

\footnotetext{
* Correspondence: rmoorehe@uoguelph.ca

* Correspondence: rmoorehe@uoguelph.ca N1G2W1 Guelph, ON, Canada
}

(C) 2011 Campbell and Moorehead; licensee BioMed Central Ltd. This is an Open Access article distributed under the terms of the

optimizing the use of such compounds will be understanding mechanisms of resistance.

The insulin-like growth factor (IGF)-axis comprises one such RTK signalling pathway heavily implicated in the progression of breast cancer and as such holds promise for therapeutic targeting. Upon activation by ligand (IGF-I or IGF-II), the IGF-IR undergoes tyrosine phosphorylation, subsequently signaling through a number of downstream pathways including MAPK and PI-3K/Akt. The mitogenicity of this receptor is well established, and is well known to contribute to transformation of normal mammary epithelial cells [2]. Effective targeting of this pathway was established in a number of xenograft models of breast cancer [3-7]. Activation of the IGF-IR is 
not correlated with any particular subtype of breast cancer [8] and therefore offers the opportunity for widespread use of targeted therapies. Based on these observations, a number of drugs targeting this pathway are currently in clinical trials $[9,10]$, including small molecule kinase inhibitors that block downstream signalling and monoclonal antibodies that block ligand receptor interactions [11]. While it is too early to determine the efficacy of such agents [9], it is of extreme importance to understand potential resistance mechanisms.

Previously our lab has created an inducible transgenic mouse model (MTB-IGFIR) of IGF-IR overexpression in which mammary tumors were observed to develop [12]. IGF-IR transgene downregulation resulted in regression of almost all established palpable tumors after which a fraction recur in the absence of IGF-IR induction [13]. Thus, this model recapitulates treatment with IGF-IRdirected therapeutics and can be used to study potential resistance mechanisms. Previous work has provided initial characterization of IGF-IR-independence and has demonstrated the presence of an epithelial-mesenchymal transition (EMT) phenotype in these recurrent tumors [13]. Subsequent microarray data, comparing primary mammary tumors to IGF-IR-independent recurrent tumors, has since identified members of the plateletderived growth factor family (PDGF) as being upregulated during this process [14].

The importance of PDGF receptors (PDGFRs) is well known in gliomas, sarcomas and gastrointestinal stromal tumors but has more recently been noted in such cancers as ovarian, prostate and neuroblastomas (reviewed in $[15,16])$. However, compared to other RTKs, little is known about the role of these proteins in breast cancer. Signalling through PDGFRs has been typically associated with proliferation and migration of mesenchymal cells and is important for these processes during mammalian development (reviewed in [17]). Through downstream mediators such as MAPK, FAK, PI-3K, Src and PLC- $\gamma$, PDGFRs also govern processes such survival, proliferation and angiogenesis (reviewed in $[15,18])$. The best understood ligands for these receptors include PDGF-A and $B$ which undergo homo- or heterodimerization to become active [16]. In breast cancer, expression of PDGFRs was initially shown to be restricted to the tumor stroma, while ligand was produced by the tumor cells $[19,20]$. However, recent evidence suggests that expression of both PDGFR $\alpha$ and $\beta$, either in the tumor tissue or stroma, is correlated with invasive breast cancers and tumor progression [21-23]. In addition, PDGFR $\alpha$ was shown to be important for maintenance of EMT, evasion of apoptosis, and metastasis in transformed mesenchymal murine mammary cells [22].
The purpose of this study was to examine the role of the PDGF-axis in mammary tumors that survive independent of IGF-IR signaling in MTB-IGFIR mice. Upon IGF-IR suppression, expression of PDGFR $\alpha$ and $\beta$ were observed to increase, a process which occurred rapidly. In cell lines isolated from IGF-IR-independent recurrent tumors, PDGFRs were shown to facilitate motility and invasion with more modest effects on proliferation and apoptosis.

\section{Materials and methods Animal studies}

MTB-IGFIR transgenic mice are described elsewhere [12]. For IGF-IR transgene induction, mice were given a diet containing $2 \mathrm{mg} / \mathrm{kg}$ doxycycline (Bio-Serv Inc., Frenchtown, NJ). Tumors were allowed to grow to a maximum length of $17 \mathrm{~mm}$ (under the guidelines of the Canadian Council of Animal Care). IGF-IR-independent recurrent tumors were formed after the withdrawal of doxycycline, and are described in [13]. For IGF-IR downregulation studies, mice harboring mammary tumors induced through administration of doxycycline were given a normal diet and tissue was collected 24 and $48 \mathrm{~h}$ later. Animals were housed and cared for following guidelines established by the Central Animal Facility at the University of Guelph and the guidelines established by the Canadian Council of Animal Care.

\section{Cell lines and culture conditions}

RM11A cells, a murine mammary tumor cell line derived from an MTB-IGFIR mammary tumor, were grown as described in [24]. Doxycycline $(10 \mu \mathrm{g} / \mathrm{mL})$ was added to the culture media for transgene induction and only omitted from the media for withdrawal studies. RJ345 cells were isolated from primary mammary tumors of MTB-IGFIR mice and cultured in media containing doxycycine as above while RJ348 and RJ423 cells were isolated from IGF-IR-independent spindle recurrent tumors; all of these cell lines were isolated and cultured in media as described in [24]. Tumors formed from all cell lines were generated through injection of approximately $5 \times 10^{5}$ cells into the $4^{\text {th }}$ mammary gland of syngeneic wild type FVB mice as described in [24]. Tumors were allowed to grow to $17 \mathrm{~mm}$ before the animal was euthanized and tissue was collected.

\section{Western blotting}

Western blotting was performed as described in [24]. Briefly, $30 \mu \mathrm{g}$ of protein lysate was subjected to SDSPAGE with subsequent transfer onto nitrocellulose membranes. Primary antibodies used included antiPDGFR $\alpha$, anti-PDGFR $\beta$, anti-phospho-Akt, anti-Akt, anti-phospho-p42/44, anti-p42/44, anti-Cyclin D1 (all from Cell Signal technology, Danvers, MA, USA), and 
anti-IGF-IR (R\&D Systems, Minneapolis, MN, USA) all used at 1:1000 as well as anti- $\beta$-actin (Cell Signaling Technology, Danvers, MA, USA) used at 1:5000. Secondary antibody was anti-rabbit IgG (Cell Signaling Technology, Danvers, MA, USA) or anti-Goat (Santa Cruz, Biotechnologies, Santa Cruz, CA) used at 1:2000. Quantification of protein levels was performed using a FluorChem 9900 imager and AlphaEaseFC software version 3.1.2 (Alpha Innotech, San Leandro, CA, USA).

\section{Immunohistochemistry}

Immunohistochemistry was performed as described in [25]. Sections cut from primary and IGF-IR-devoid recurrent tumors described in [13] were used. Antibodies used were anti-PDGFR $\alpha$ and anti-PDGFR $\beta$; both were used at 1:100 (Cell Signaling Technology, Danvers, MA, USA). Biotinylated anti-rabbit secondary antibody (Sigma-Aldrich, St. Louis, MO) was used for both at a concentration of 1:200. Images were captured using light microscopy.

\section{Real time PCR}

Real time PCR was performed to quantify transcript levels. RNA was isolated using a mirVANA kit (Ambion, Streetsville, ON) in accordance with the manufacturer's instructions (without the miRNA enrichment step). Reverse transcription and real time PCR was performed as described in [13]. Primers specific genes encoding human IGF-IR [13], as well as PDGFR $\alpha$ and PDGFR $\beta$ (both obtained from Origene, Rockville, MD) were used. The hypoxanthine-guanine phosphoribosyltransferase (HPRT) gene was used for normalization.

\section{Transfections and siRNA-mediated protein knockdown}

Transient transfections were performed using Lipofectamine (Invitrogen, Burlington, $\mathrm{ON}$ ) in accordance with the manufacturer's directions. RNA oligonucleotides were transfected at a final concentration of $200 \mathrm{pmol} /$ $\mathrm{mL}$. Briefly, three Stealth siRNA oligonucleotides with binding specificity for murine IGF-IR, PDGFR $\alpha$ or PDGFR $\beta$ mRNA (Invitrogen, Burlington, ON) were originally tested for their ability to diminish expression of these gene products through western blotting. An appropriate GC control oligonucleotide (Invitrogen, Burlington, $\mathrm{ON}$ ) was used as a negative control.

\section{MTT survival assays}

MTT survival assays were performed as described in [24]. Briefly, 500 cells/well were plated in 96-well plates in triplicate. Two days after seeding, cells were transfected with siRNA as indicated above. Three days later, MTT was added to the cells which were subsequently lysed after $1 \mathrm{~h}$. Values are reported relative to the corresponding GC control and represent the average of 5 trials.

\section{Immunofluorescence}

Immunofluorescence was performed as described in [25]. To assess proliferation, cells plated on coverslips were transfected with siRNA oligonucleotides specific for PDGFR $\alpha$, PDGFR $\beta$ or both as described above. Forty-eight hours after siRNA treatement, cells were fixed with $10 \%$ formalin for $1 \mathrm{~h}$ at room temperature and stained for Ki67. Primary antibody, anti-Ki67 (Abcam, Cambridge, MA), was used at a concentration of 1:200, while antibodies specific for cleaved Caspase-3 and phospho-HistoneH3 (both from Abcam, Cambridge, MA) were both used at 1:100; fluorescent conjugated Alexafluor secondary antibody (Invitrogen, Burlington, $\mathrm{ON}$ ) was used at a dilution of 1:2000. Images were taken using using an Olympus BX61 fluorescent microscope (Center Valley, PA) with MetaMorph version 7.6.0.0 software (Molecular Devices, Downington, PA) at a magnification of $100 \times$. Positive nuclei from 5-10 fields of view were counted; results represent the average positivity compared to respective controls from three independent trials.

\section{JC- 1 assays}

JC-1 assays were employed to test apoptosis after downregulation of PDGFRs. Recurrent cell lines were plated in 12-well plates. Twenty-four hours later cells were transfected with RNAi as outlined above. Fortyeight hours post-transfection, media was removed and fresh media containing JC-1 (Invitrogen, Burlington, $\mathrm{ON}$ ) at a concentration of $200 \mu \mathrm{g} / \mathrm{mL}$ was added to the cells. Cells were incubated with JC1 for $15 \mathrm{~min}$ at $37^{\circ} \mathrm{C}$, after which media was removed and wells were washed three times with PBS. Images were captured using an Olympus IX81 microscope (Olympus, Markham, ON) at $200 \times$ magnification using Image Pro Plus V.5.0.2.9 software (MediaCybernetics, Bethesda, $\mathrm{MD}$ ) with the green fluorescent protein (GFP) channel (485-535 nm).

\section{Scratch assays}

For scratch tests, cells were plated in 12-well plates such that they were $90-100 \%$ confluent at the time the scratch was performed. Transient transfection with siRNA (as stated above) was performed $48 \mathrm{~h}$ after the cells were seeded. A single scratch was made down the center of the well with a $200 \mu \mathrm{L}$ pipette tip $4 \mathrm{~h}$ post transfection. Subsequently media was removed, cells were washed twice with PBS and media was replaced. Cells were imaged at various timepoints (including immediately after the scratch was produced, $0 \mathrm{~h}$ ) using an Olympus IX81 microscope (Olympus, Markham, $\mathrm{ON})$ at $100 \times$ magnification and Image Pro Plus V.5.0.2.9 software (MediaCybernetics, Bethesda, MD). This experiment was replicated four times. 


\section{Invasion assays}

Recurrent cell lines were transfected with siRNA as described above. Cell invasion was assessed using $8 \mu \mathrm{m}$ BioCoat $^{\mathrm{TM}}$ Matrigel invasion chambers (BD Biosciences, Franklin Lakes, NJ, USA) 24 h after transfection. Chambers were placed in 12-well dishes and the top and bottom compartment were rehydreated with serum free and full serum media (DMEM containing only glutamine, sodium pyruvate, antibiotic/antimycotic and HEPES buffer) respectively for two hours at $37^{\circ} \mathrm{C}$. Subsequently, $2.0 \times 10^{4}$ RJ348 or $1.0 \times 10^{5}$ RJ423 cells (previously transfected) suspended in either 200 or $500 \mu \mathrm{L}$ of serum free media were plated in the upper chamber, while $300 \mu \mathrm{L}$ of fresh full serum media was added to the bottom chamber. Invasion was allowed to proceed for $24 \mathrm{~h}$ at $37^{\circ} \mathrm{C}$. At this time, $500 \mu \mathrm{L}$ of $5 \%$ gluteraldehyde was added to the bottom chamber and invading cells were fixed for $10 \mathrm{~min}$. Subsequently, wells were washed three times with distilled water and incubated with $0.5 \%$ toluidine blue for $20 \mathrm{~min}$. Liquid was then aspirated from both chambers and the lower chamber was washed three times with water. A cotton swab was used to wipe the inner surface of the upper chamber to remove non-invasive cells. Invading cells were visualized and images were captured using an Olympus IX81 microscope (Olympus, Markham, ON) at $20 \times$ magnification and Image Pro Plus V.5.0.2.9 software (MediaCybernetics, Bethesda, MD). Cells were counted from 3-4 fields of view and the average number of invading cells per field of view was expressed relative to respective controls. Results represent the average of three replicates.

\section{Statistics}

Results are presented as the mean \pm standard error. Statistical significance was assessed through either a student's $t$-test (for analyzing two means) or analysis of variance (ANOVA) followed by a post hoc Tukey test (for more than two means).

\section{Results \\ PDGFRs are overexpressed in IGF-IR-independent mammary tumors}

A previous study from our lab showed that downregulation of the IGF-IR transgene in established mammary tumors in MTB-IGFIR transgenic mice resulted in stable regression of a majority of the tumors, however, a small proportion of the tumors resumed growth and expressed only very low levels of IGF-IR [13]. A DNA microarray was then performed on wild type mammary tissue, mammary tumors induced by high levels of the IGF-IR transgene (also called primary mammary tumors or PMTs) and mammary tumors that resumed growth following IGF-IR transgene downregulation that only expressed low levels of IGF-IR (also called IGF-IR-independent recurrent spindle tumors or RSTs). The microarray data indicated that both PDGFR $\alpha$ and PDGFR $\beta$ were upregulated in the IGF-IR-independent, recurrent tumors compared to the IGF-IR-dependent, primary tumors [14]. Based on these findings it was hypothesized that PDGFR overexpression is important for tumor survival following IGF-IR downregulation.

As a first step, western blotting was performed for PDGFR $\alpha$ and PDGFR $\beta$ in primary mammary tumors (IGF-IR-dependent) and IGF-IR-dependent recurrent tumors of MTB-IGFIR transgenic mice. Although there was some inter-tumor variability, the IGF-IR-independent recurrent spindle tumors displayed an overall increase in both PDGFR $\alpha$ and PDGFR $\beta$, with some tumors displaying especially high levels (Figure 1a). Expression of PDGFRs was also assessed using immunohistochemistry. In primary tumors, only sparse expression of both PDGFR $\alpha$ and $\beta$ was observed (Figure 1b-e) while in IGF-IR-independent recurrent tumors, these receptors were often found to be highly expressed (Figure 1f-i).

\section{PDGFRs are inversely regulated with IGF-IR expression}

To determine if PDGFRs were rapidly upregulated in response to IGF-IR downregulation, MTB-IGFIR transgenic mice with palpable mammary tumors were switched to normal food (not containing doxycycline). IGF-IR levels were previously shown to decrease dramatically at $24 \mathrm{~h}$ and $48 \mathrm{~h}$ following doxycycline withdrawal [13]. As shown in Figure 2a, both PDGFR $\alpha$ and PDGFR $\beta$ were observed to increase at both time points evaluated ( $24 \mathrm{~h}$ and $48 \mathrm{~h}$ ). Consistent with the western blot data, qRT-PCR analysis revealed that IGF-IR mRNA was significantly decreased in the mammary tumors following doxycycline withdrawal while the levels of PDGFR $\alpha$ and PDGFR $\beta$ mRNA were elevated at least 2.9-fold (Table 1).

To further validate the induction of PDGFR $\alpha$ and PDGFR $\beta$ following IGF-IR transgene downregulation several cell lines were utilized. First, a cell line established from a primary, IGF-IR-dependent mammary tumor (RJ345) and two cell lines from unique IGF-IRindependent recurrent tumors (RJ348 and RJ423) were examined. The RJ345 cells maintained high levels of IGF-IR while the RJ348 and RJ423 cells expressed much lower levels of IGF-IR. Consistent with the in vivo findings, tumor cells expressing low levels of IGF-IR (RJ348 and RJ423) expressed high levels of PDGFR $\alpha$ and PDGFR $\beta$ compared to the RJ345 cells (Figure 2b).

Next, the RM11A cell line was examined in vitro and in vivo. The RM11A cell line was also established from a MTB-IGFIR mammary tumor and this cell line has been more extensively characterized [23]. The RM11A cells express high levels of IGF-IR when cultured in the presence of doxycycline and only express low levels of 


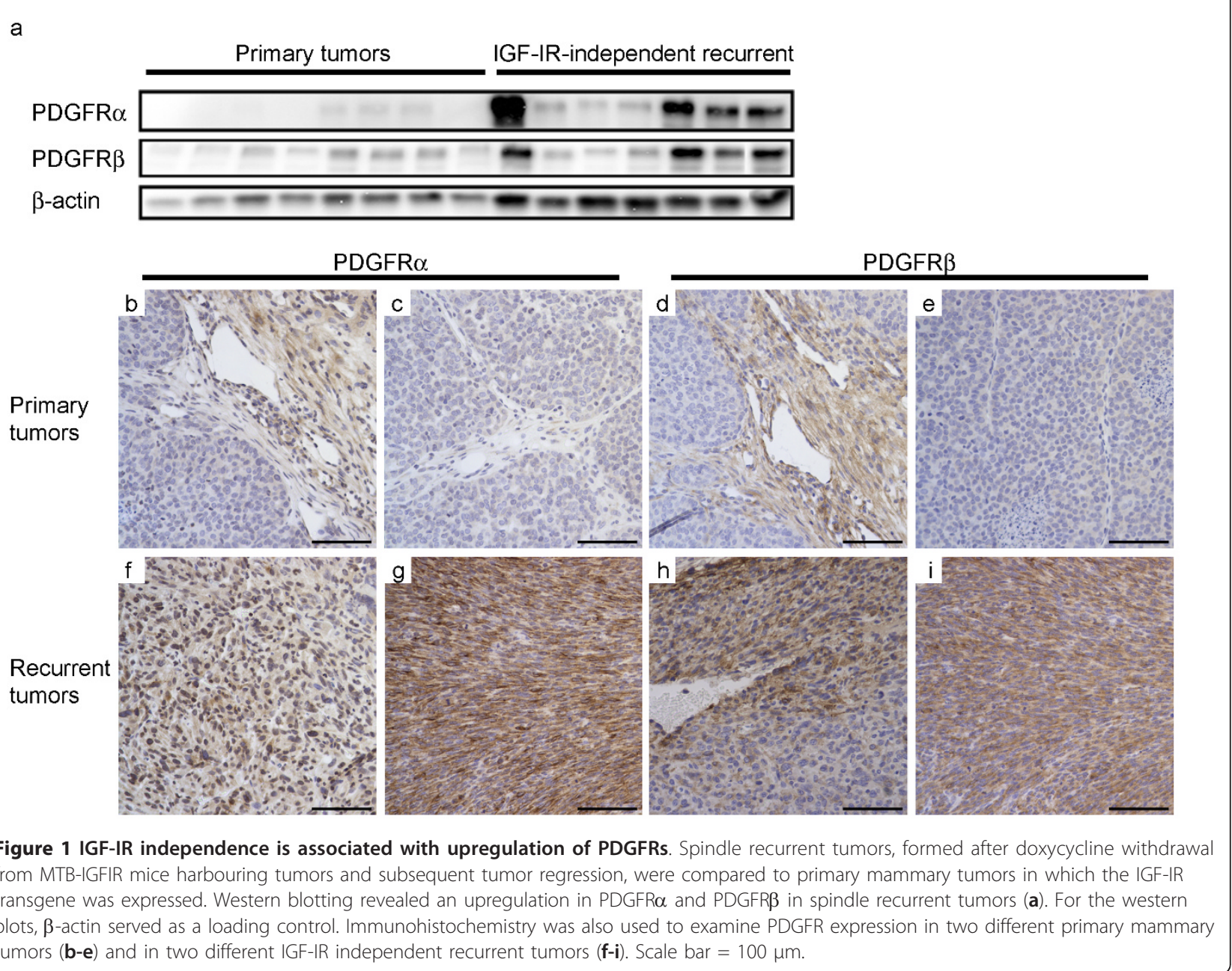

IGF-IR when cultured in the absence of doxycycline both in vitro and in vivo [24]. In addition, the RM11A cells can be injected into the mammary fat pad of syngeneic, FVB mice and these cells form mammary tumors faster in the presence of doxycycline than in the absence of doxycycline [23]. Evaluation of PDGFR $\alpha$ and PDGFR $\beta$ in RM11A cells grown in vitro in the presence of doxycycline or in four independent clones grown in the absence of doxycycline for at least four passages revealed that both PDGFR $\alpha$ and PDGFR $\beta$ levels increased in the clones expressing low levels of IGF-IR (Figure 2c). A similar increase in PDGFR $\alpha$ and PDGFR $\beta$ levels was observed in RM11A cells grown in vivo in the absence of doxycycline compared to RM11A cells grown in vivo in the presence of doxycycline (Figure 2d).

\section{Downregulation of PDGFRs in IGF-IR-independent recurrent cell lines results in increased survival} To further evaluate the function of PDGFR $\alpha$ and PDGFR $\beta$ in mammary tumor cells that have become independent of IGF-IR signaling, PDGFR $\alpha$ or PDGFR $\beta$ were knocked down alone, or in combination, in two IGF-IR-independent mammary tumor cell lines, RJ348 and RJ423. These two cell lines were chosen as they express high levels of PDFGR $\alpha$ and PDGFR $\beta$ and low levels of IGF-IR (Figure 2b).

Downregulation of PDGFR $\alpha$ or $\beta$ alone or in combination was consistently achieved in both cell lines and was validated up to $72 \mathrm{~h}$ post transfection (Figure 3). Knockdown of either receptor isoform did not result in downregulation of the other. Concomitant administration of siRNA for PDGFR $\alpha$ and PDGFR $\beta$ was effective at reducing the expression of both PDFGRs (Figure 3).

Interestingly, with PDGFR knockdown, Akt activation increased in both recurrent cell lines (Figure 3). With pErk $1 / 2$, levels increased with PDGFR knockdown in RJ348 cells; however, in RJ423 cells, this protein was observed to have slightly decreased levels. Cyclin D1, an important molecule in our model [12,24], was 


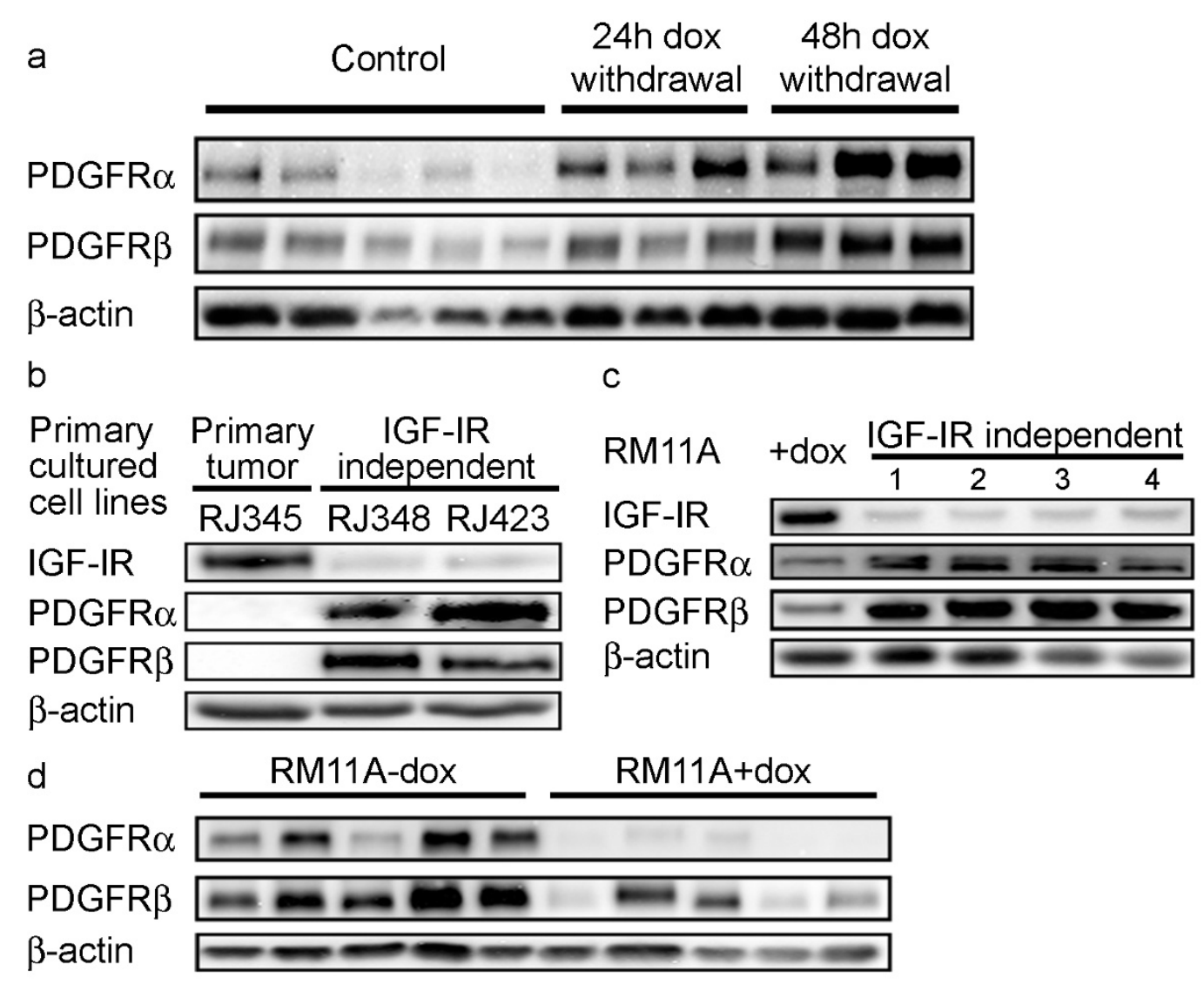

Figure 2 PDGF receptors are inversely regulated with IGF-IR. Western blotting was used to examine expression in response to varying IGF-IR levels. Doxycycline was withdrawn from MTB-IGFIR mice with mammary tumors and tissue was collected 24 or $48 \mathrm{~h}$ later. Levels of PDGFRs were assessed and compared to that of tumors with IGF-IR induction (a). IGF-IR and PDGFR expression in a cell line (RJ345) created from a IGF-IRdependent primary mammary tumor and two cell lines (RJ348 and RJ348) created from different IGF-IR-independent recurrent spindle tumors (b). Four cell clones expressing low levels of IGF-IR were generated through serial passage in the absence of doxycycline. Confirmation of IGF-IR downregulation as well as determination of PDGFR $\alpha$ and PDGFR $\beta$ levels was performed (c). PDGFR levels in RM11A cells grown in vivo with (RM11A + dox) or without (RM11A-dox) doxycycline induction. Tissue was collected when tumors reached $17 \mathrm{~mm}$ in diameter (d). For all Western blots, $\beta$-actin served as a loading control.

unchanged after PDGFR downregulation (Figure 3). Three trials were performed to confirm these findings.

It was expected that given the dramatic increase in PDGFR expression in recurrent tumors and cells, this pathway would be important for cell proliferation and survival. To test this hypothesis, MTT assays were performed. Contrary to expectations, cell number increased by approximately 1.7 and 1.5 -fold with PDGFR $\alpha$ knockdown in RJ348 and RJ423 cells, respectively. A more modest 1.4 and 1.2-fold increase in cell number was observed with downregulation of PDGFR $\beta$, while dual knockdown increased cell number by 2.0 and

Table 1 Expression of PDGFR transcripts after suppression of IGF-IR levels

\begin{tabular}{llll}
\hline RM11A cell line (in vitro) & IGF-IR & PDGFR & PDGFR $\beta$ \\
\hline with doxycycline & $1.000 \pm 0.000$ & $1.000 \pm 0.000$ & $1.000 \pm 0.000$ \\
\hline without doxycycline & $0.042 \pm 0.024$ & $1.608 \pm 1.087$ & $2.953 \pm 0.534$ \\
\hline MTB-IGFIR transgenic (in vivo) & & $1.000 \pm 0.210$ \\
\hline Control & $1.000 \pm 0.223$ & $1.000 \pm 0.392$ & $3.193 \pm 0.948$ \\
\hline 24 h doxycycline withdrawal & $0.010 \pm 0.006$ & $3.113 \pm 1.620$ & $2.917 \pm 0.818$ \\
\hline 48 h doxycycline withdrawal & $0.004 \pm 0.002$ & $7.527 \pm 2.475^{*}$ & \\
\hline
\end{tabular}

*Statistically significant compared to control (with doxycycline) $p<0.05$. 


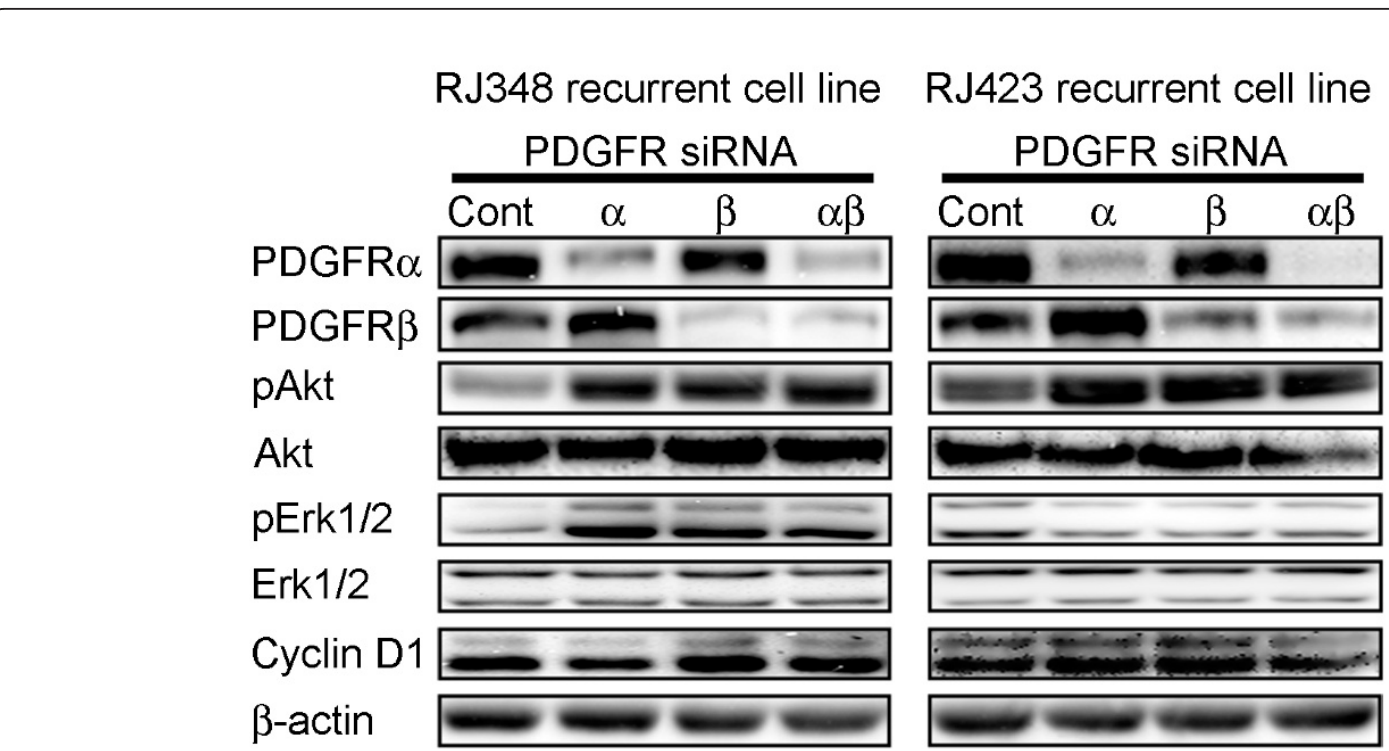

Figure 3 siRNA mediated downregulation of PDGFRs. RJ348 and RJ423 recurrent cell lines were plated and $48 \mathrm{~h}$ later they were transiently transfected with oligonucleotides specific for either PDGFR $\alpha$, $\beta$ or both; an appropriate GC oligonucleotide was used as a control. Seventy-two hours post-transfection, protein was collected and subjected to western blotting probing for both PDGF receptors as well as pAkt, Akt, pErk1/2, Erk1/2 and cyclin D1. $\beta$-actin served as a loading control.

1.8-fold in RJ348 and RJ423 cells, respectively (Figure 4a). To determine if this effect was due to changes in proliferation or apoptosis, subsequent assays were performed.

Apoptosis was addressed by using both JC-1 assays and staining for cleaved caspase- 3 after knocking down PDGFRs. JC1 assays are based on the detection of loss of mitochondrial membrane potential, a hallmark of apoptosis, using a lipophilic cationic dye 5,5', 6,6'-tetrachloro-1,1',3,3' -tetraethylbenzimidazolcarbocyanide dye (JC-1); this dye naturally exhibits a green fluorescence during low membrane potential, but changes to red fluorescence as membrane potential increases. Thus cells staining intensely green are counted as apoptotic [26]. As seen in Figure 4b and 4c, knockdown of PDGFR $\alpha$ resulted in a substantial decrease in apoptosis in both cell lines, while PDGFR $\beta$ downregulation resulted in a more modest insignificant decrease in apoptosis. Little further decrease in apoptosis, compared to PDGFR $\alpha$ knockdown, was observed when both isoforms were targeted as assessed through both aforementioned assays (Figure $4 \mathrm{~b}, \mathrm{c}$ ).

Proliferation after PDGFR downregulation was quantified through staining for Ki67, a well-known marker of proliferation, and phosphorylated HistoneH3. As seen in Figure $4 \mathrm{~d}$ and $4 \mathrm{e}$, PDGFR $\alpha$ as well as dual PDGFR knockdown resulted in an almost identical increase in relative Ki67 and pHistoneH3 positivity of approximately 1.6-fold and 1.3-fold respectively in both cell lines. In
RJ348 cells, PDGFR $\beta$ had no effect on Ki67 positivity. In RJ423 cells, knockdown of this receptor isoform had variable results with an average overall increase in Ki67 staining of approximately 1.8-fold (Figure 4d). PDGFR $\beta$ knockdown had only a minimal effect on phospho-HistoneH3 staining in both cell lines (Figure 4e). Only downregulation of both PDGFR isoforms resulted in a significant increase in proliferation (Figure 4d, e).

PDGFR knockdown in recurrent cell lines impairs migration and invasion

To assess the importance of PDGFRs for cell migration in these recurrent cell lines, scratch wound assays were employed after downregulation of PDGFRs. Images were captured at various timepoints after the scratch wound was made and images shown are representative of four trials (Figure 5). As shown, in the RJ348 cell line, control cells had penetrated the wound by $14 \mathrm{~h}$ and wounds were observed to be virtually filled by $28 \mathrm{~h}$. With knockdown of either PDGFR $\alpha$ or $\beta$, a slight impairment was observed after $14 \mathrm{~h}$; however, after $28 \mathrm{~h}$ no differences were seen compared to control cells. When both receptor isoforms were downregulated, cells did not begin to fill the wound until after $14 \mathrm{~h}$ and even after $28 \mathrm{~h}$, many large gaps devoid of cells were observed (Figure 5a). For RJ423 cells a similar trend was observed; a dramatic reduction in migration was observed after knocking down individual PDGFR isoforms or both isoforms at the first timepoint, $16 \mathrm{~h}$. At the second timepoint, 40 




h, control cells had almost completely filled the wound; with knockdown of either PDGFR $\alpha$ or $\beta$, relatively large gaps were still observed and with dual knockdown, very little progress had been made in filling the wound (Figure 5b). With knockdown of either PDGFR isoform, it took approximately $45 \mathrm{~h}$ for the wound to be completely filled, while with dual knockdown, wounds finally were filled by $72 \mathrm{~h}$ (data not shown).

A system utilizing matrigel coated membranes was employed to assess the role of PDGFRs in extracellular 


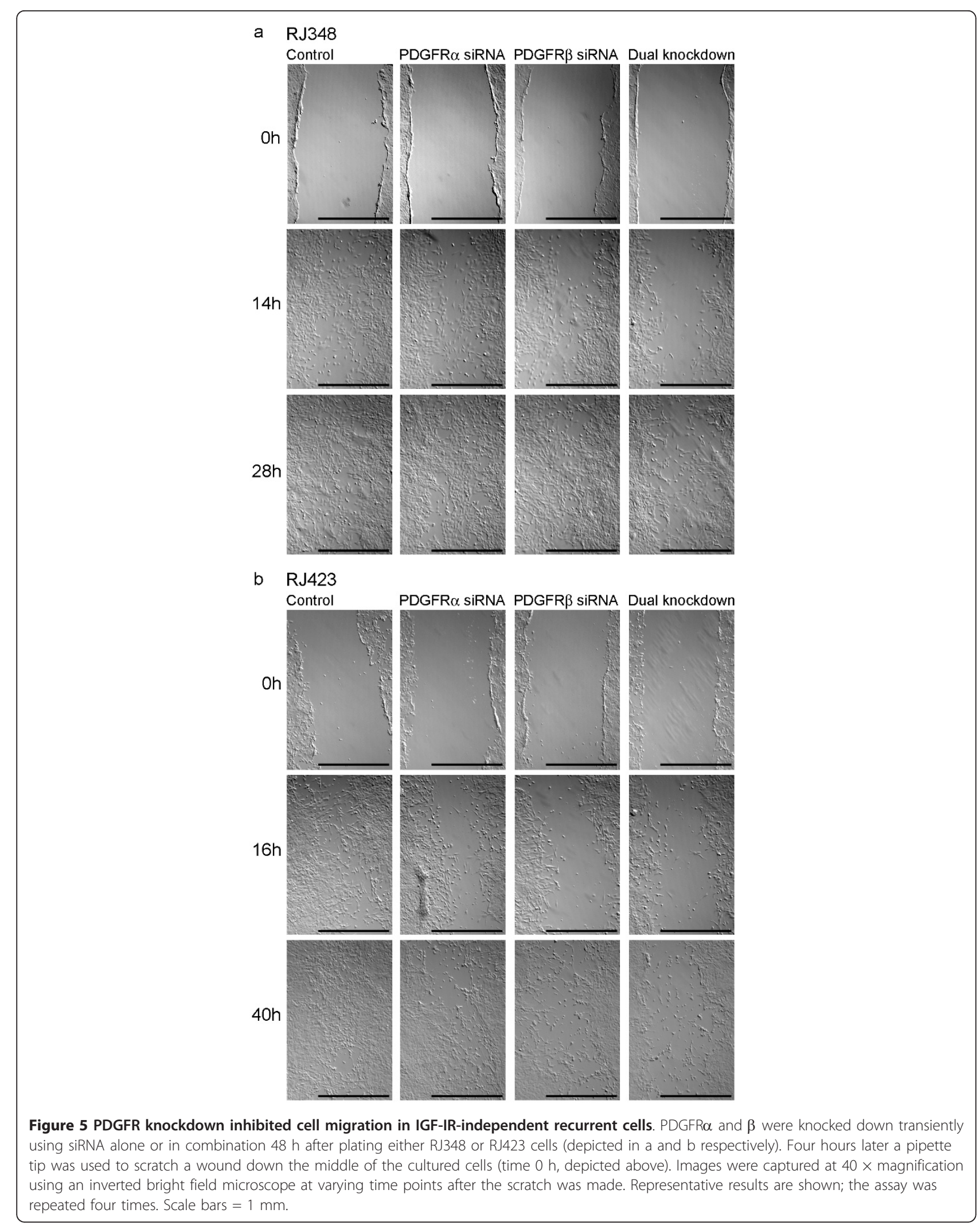




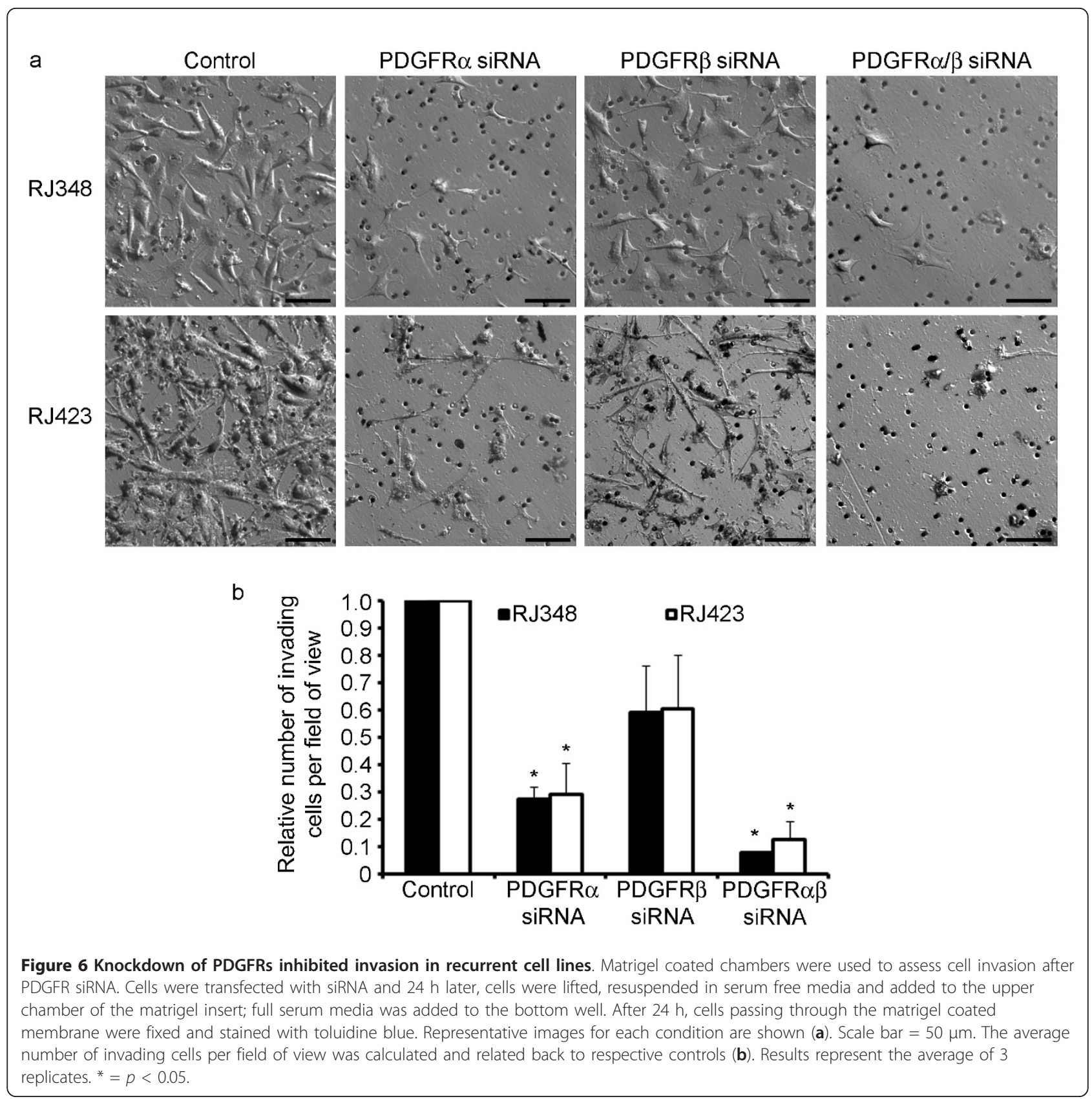

matrix (ECM) invasion in these recurrent cells (Figure 6a). Downregulation of PDGFR $\alpha$ in both cell lines resulted in a statistically significant decrease in invasion of approximately $70 \%$, while PDGFR $\beta$ knockdown inhibited invasion by approximately $40 \%$ (not determined to be statistically significant) (Figure 6b). Dual knockdown of both PDGFR isoforms resulted in an even greater increase in invasion inhibition compared to downregulation of either isoform alone (92\% and $88 \%$ inhibition for RJ348 and RJ423 respectively).

\section{Discussion}

While IGF-IR-targeting drugs hold promise for the treatment of breast cancer, based on what is known of other such targeted therapeutics, resistance is sure to be a major roadblock for the treatment of certain patients. Our work on the MTB-IGFIR transgenic mice supports the hypothesis that some tumors, although initially dependent on IGF-IR signaling for growth, can become independent of IGF-IR signaling. We found that downregulation of the IGF-IR transgene (through removal of doxycycline) in established mammary tumors led to the 
regression of most of the mammary tumors. However approximately $11 \%$ of the tumors resumed growth following IGF-IR transgene downregulation and these tumors no longer expressed high levels of IGF-IR [13]. Analysis at both the mRNA and protein level revealed that PDGFR $\alpha$ and PDGFR $\beta$ were consistently upregulated in tumor cells and tumor tissue following loss of IGF-IR expression. Therefore, one change that occurs during IGF-IR independent tumor growth is the upregulation of PDGFR signaling.

Although this reciprocal expression pattern has not been described previously in breast cancer, it has been observed in a rhabdomyosarcoma cell line selected for resistance to BMS-754807 (an IGF-IR small molecule inhibitor) [27]. In this study, administration of increasing concentrations of BMS-75807 to Rh41 cells for approximately 5 months resulted in the generation of a clone resistant to BMS-754807. The BMS-754907-resistant clone expressed lower levels of IGF-IR and elevated levels of PDGFR $\alpha$ compared to the parental cells. In addition, the investigators found that the combination of an anti-IGF-IR agent with an anti-PDGFR $\alpha$ agent resulted in synergistic cell kill [27]. A reciprocal relationship between IGF-IR and PDGFR $\alpha / \mathrm{c}-$ kit expression has also been observed in gastrointestinal stromal tumors [28]. Therefore, it appears that PDGFR signaling is enhanced following the loss of IGF-IR signaling and vice versa, an important concept to considering when designing therapeutic strategies targeting either of these receptors.

To determine the functional consequence of elevated PDGFR $\alpha$ and PDGFR $\beta$, cell survival, proliferation, apoptosis and migration/invasion were evaluated following RNAi-mediated knockdown of PDGFR $\alpha$ and PDGFR $\beta$ alone or concomitant knockdown of both receptors. The most dramatic effect was the decrease in migration and invasion following concomitant knockdown of both PDGFRs. In other systems, PDGFR $\beta$ has previously been shown to promote cell migration, while PDGFR $\alpha$ has been shown to inhibit this process [29-31]. However, more recently, it was shown that both receptors could promote migration in fibroblasts with additive effects when both were present [18]. Similar to these results, the greatest inhibitory effect on migration was observed in this study when both isoforms were knocked down compared to either one individually. Analogous to our findings, in human breast cancer cell lines, PDGF ligands have also previously been shown to mediate invasion or upregulate markers of invasion $[32,33]$. These processes are important for metastasis and it will be interesting to determine if the PDGF-axis is involved in metastasis in our model, especially during IGF-IRindependent recurrence. Previously, in a model of ras- transformed mammary epithelial cells undergoing EMT, PDGFR inhibition was shown to impede metastasis [22].

Somewhat surprisingly, downregulation of both PDGFRs resulted in a modest increase in proliferation and a decrease in apoptosis. These results are not in accordance with conventional models of PDGFR signaling. Typically this pathway is involved in survival and proliferation for mesenchymal cells including a number of cancers of mesenchymal origin such as dermatofibrosarcoma protuberans, gastrointestinal stromal tumors, chronic myeloid leukemias and gliomas [15,34]. However, the mitogenic and transforming effect of PDGFRs in other tumor types of epithelial origin, including breast cancer, remains largely unknown. While targeting the PDGFR usually results in inhibition of cell survival [35], similar results to ours have been reported in other models; PDGFR $\alpha$ overexpression was shown to inhibit melanoma tumor cell growth in vitro and in vivo [36], while overexpression of PDGF-BB in human pancreatic and colorectal cells resulted in a reduction in tumor growth [37].

Interestingly, the levels of phosphorylated Akt were elevated in both cell lines following downregulation of PDGFRs. This observation is in contrast to published reports indicating that PDGFRs signal via Akt [38], but would explain why an increase in proliferation and a decrease in apoptosis was observed following PDGFR downregulation. Phosphorylated Akt initiates signals that promote cell proliferation and inhibits apoptosis [39-41]. Therefore, activation of a signaling pathway other than the PDGFRs must compensate for the loss of IGF-IR signaling and maintain high levels of Akt phosphorylation in our model. One logical receptor family would be the EGFR/ErbB family as these receptors have been shown to mediate resistance to IGF-IR targeting agents in some models [42-44]. However, western blotting of IGF-IR-dependent and IGF-IR-independent mammary tumors did not show any consistent differences in the levels of EGFR, ErbB2 or ErbB3 or the phosphorylated forms of these receptors (data not shown).

Recently we have shown that mammary tumors that become independent of IGF-IR signaling in MTB-IGFIR transgenic mice and the RJ348 cell line have characteristics of claudin-low breast tumors [14,45]. The claudinlow breast cancer subtype was identified in 2007 and is characterized by low levels of claudins 3,4 and 7 as well as other tight junction proteins $[46,47]$. Claudin-low tumors also express high levels of markers associated with epithelial-to-mesenchymal transition (EMT) such as Twist1/2, Zeb1/2, Slug and Snail while expressing little or no markers of luminal differentiation [46]. The prevalence of claudin-low tumors is reported to be 
7-14\% and claudin-low tumors have a prognosis similar to luminal B, HER2 enriched and basal-like breast cancers [47]. Claudin-low subtypes have been reported to most closely resemble mammary epithelial stem cells [47]. Therefore, it is possible that claudin-low tumors present with elevated levels of PDGFR $\alpha$ and PDGFR $\beta$, a characteristic that may improve the treatment of this class of tumor.

In conclusion, loss of IGF-IR signaling is associated with an increase in PDGFR $\alpha$ and PDGFR $\beta$ expression. This increase in PDGFRs appears to enhance migration and invasion of mammary tumor cells. This phenomenon could have important clinical implications in that treatment with anti-IGFIR agents may result in an increase in PDGFR expression and enhanced metastatic capacity of breast cancer cells. Therefore, it may be important to combine anti-IGF-IR strategies with agents inhibiting PDGFR signaling to effectively eradicate tumor cells and to prevent metastasis of any tumor cells that become resistant to the anti-IGFIR therapy. Alternatively, elevation of PDGFRs may be a characteristic of claudin-low tumors and this feature may be exploited to improve the treatment of this breast cancer subtype.

\section{Acknowledgements}

This work was supported through a grant from the Canadian Breast Cancer Foundation - Ontario Chapter to RM.

\section{Authors' contributions}

CC participated in design and coordination of the study as well as all of the experiments described in this study and drafting of the manuscript. RM coordinated the study and contributed to drafting of the manuscript. All authors have read and approved the final manuscript.

\section{Competing interests}

The authors declare that they have no competing interests.

Received: 2 September 2011 Accepted: 9 November 2011

Published: 9 November 2011

\section{References}

1. Nahta R, Yu D, Hung MC, Hortobagyi GN, Esteva FJ: Mechanisms of Disease: understanding resistance to HER2-targeted therapy in human breast cancer. Nat Clin Pract Oncol 2006, 3:269-280.

2. Kleinberg DL, Wood TL, Furth PA, Lee AV: Growth hormone and insulinlike growth factor-I in the transition from normal mammary development to preneoplastic mammary lesions. Endocr Rev 2009, 30:51-74.

3. Arteaga C, Kitten K, Coronado E: Blockade of the type I somatomedin receptor inhibits growth of human breast cancer cells in athymic mice. $J$ Clin Invest 1989, 84:1418-1423.

4. Burtrum D, Zhu Z, Lu D, Anderson DM, Prewett M, Pereira DS, et al: A fully human monoclonal antibody to the insulin-like growth factor I receptor blocks ligand-dependent signaling and inhibits human tumor growth in vivo. Cancer Res 2003, 63:8912-8921.

5. Chernicky CL, Yi L, Tan H, Gan SU, llan J: Treatment of human breast cancer cells with antisense RNA to the type I insulin-like growth factor receptor inhibits cell growth, suppresses tumorigenesis, alters the metastatic potential, and prolongs survival in vivo. Cancer Gene Ther 2000, 7:384-395.

6. Chernicky $\mathrm{CL}$, Tan H, Yi L, Loret dM Jr, llan J: Treatment of murine breast cancer cells with antisense RNA to the type I insulin-like growth factor receptor decreases the level of plasminogen activator transcripts, inhibits cell growth in vitro, and reduces tumorigenesis in vivo. $\mathrm{Mol}$ Pathol 2002, 55:102-109.

7. Salatino M, Schillaci R, Proietti CJ, Carnevale R, Frahm I, Molinolo AA, et al: Inhibition of in vivo breast cancer growth by antisense oligodeoxynucleotides to type I insulin-like growth factor receptor mRNA involves inactivation of ErbBs, Pl-3 K/Akt and p42/p44 MAPK signaling pathways but not modulation of progesterone receptor activity. Oncogene 2004, 23:5161-5174.

8. Law JH, Habibi G, Hu K, Masoudi H, Wang MY, Stratford AL, et al: Phosphorylated insulin-like growth factor-i/insulin receptor is present in all breast cancer subtypes and is related to poor survival. Cancer Res 2008, 68:10238-10246.

9. Gualberto A, Pollak M: Emerging role of insulin-like growth factor receptor inhibitors in oncology: early clinical trial results and future directions. Oncogene 2009, 28:3009-3021.

10. Weroha SJ, Haluska P: IGF-1 receptor inhibitors in clinical trials-early lessons. J Mammary Gland Biol Neoplasia 2008, 13:471-483.

11. Byron SA, Yee D: Potential therapeutic strategies to interrupt insulin-like growth factor signaling in breast cancer. Semin Oncol 2003, 30:125-132.

12. Jones RA, Campbell Cl, Gunther EJ, Chodosh LA, Petrik JJ, Khokha R, et al: Transgenic overexpression of IGF-IR disrupts mammary ductal morphogenesis and induces tumor formation. Oncogene 2007, 26:1636-1644.

13. Jones RA, Campbell Cl, Wood GA, Petrik JJ, Moorehead RA: Reversibility and recurrence of IGF-IR-induced mammary tumors. Oncogene 2008, 13:407-413.

14. Franks SE, Campbell Cl, Barnett EF, Siwicky MD, Livingstone J, Cory S, et al: Transgenic IGF-IR overexpression induces mammary tumors with basallike characteristics while IGF-IR independent mammary tumors express a claudin-low gene signature. Oncogene 2011.

15. Alvarez RH, Kantarjian HM, Cortes JE: Biology of platelet-derived growth factor and its involvement in disease. Mayo Clin Proc 2006, 81:1241-1257.

16. Fredriksson L, Li H, Eriksson U: The PDGF family: four gene products form five dimeric isoforms. Cytokine Growth Factor Rev 2004, 15:197-204.

17. Betsholtz C: Biology of platelet-derived growth factors in development. Birth Defects Res C Embryo Today 2003, 69:272-285.

18. Yu J, Ustach C, Kim HR: Platelet-derived growth factor signaling and human cancer. J Biochem Mol Biol 2003, 36:49-59.

19. Bhardwaj B, Klassen J, Cossette N, Sterns E, Tuck A, Deeley R, et al: Localization of platelet-derived growth factor beta receptor expression in the periepithelial stroma of human breast carcinoma. Clin Cancer Res 1996, 2:773-782.

20. Coltrera MD, Wang J, Porter PL, Gown AM: Expression of platelet-derived growth factor B-chain and the platelet-derived growth factor receptor beta subunit in human breast tissue and breast carcinoma. Cancer Res 1995, 55:2703-2708.

21. Carvalho I, Milanezi F, Martins A, Reis RM, Schmitt F: Overexpression of platelet-derived growth factor receptor alpha in breast cancer is associated with tumour progression. Breast Cancer Res 2005, 7:R788-R795.

22. Jechlinger M, Sommer A, Moriggl R, Seither P, Kraut N, Capodiecci P, et al: Autocrine PDGFR signaling promotes mammary cancer metastasis. J Clin Invest 2006, 116:1561-1570.

23. Paulsson Y, Hammacher A, Heldin CH, Westermark B: Possible positive autocrine feedback in the prereplicative phase of human fibroblasts. Nature 1987, 328:715-717.

24. Jones RA, Campbell Cl, Petrik JJ, Moorehead RA: Characterization of a novel primary mammary tumor cell line reveals that cyclin D1 is regulated by the type I insulin-like growth factor receptor. Mol Cancer Res 2008, 6:819-828.

25. Linnerth NM, Baldwin M, Campbell C, Brown M, McGowan H, Moorehead RA: IGF-II induces CREB phosphorylation and cell survival in human lung cancer cells. Oncogene 2005

26. Salvioli S, Ardizzoni A, Franceschi C, Cossarizza A: JC-1, but not DiOC6(3) or rhodamine 123 , is a reliable fluorescent probe to assess delta psi changes in intact cells: implications for studies on mitochondrial functionality during apoptosis. FEBS Lett 1997, 411:77-82.

27. Huang F, Hurlburt W, Greer A, Reeves KA, Hillerman S, Chang H, et al: Differential mechanisms of acquired resistance to insulin-like growth factor-i receptor antibody therapy or to a small-molecule inhibitor, BMS- 
754807, in a human rhabdomyosarcoma model. Cancer Res 2010, 70:7221-7231.

28. Tarn C, Rink L, Merkel E, Flieder D, Pathak H, Koumbi D, et al: Insulin-like growth factor 1 receptor is a potential therapeutic target for gastrointestinal stromal tumors. Proc Natl Acad Sci USA 2008, 105:8387-8392.

29. Siegbahn A, Hammacher A, Westermark B, Heldin CH: Differential effects of the various isoforms of platelet-derived growth factor on chemotaxis of fibroblasts, monocytes, and granulocytes. J Clin Invest 1990, 85:916-920

30. Vassbotn FS, Ostman A, Siegbahn A, Holmsen H, Heldin CH: Neomycin is a platelet-derived growth factor (PDGF) antagonist that allows discrimination of PDGF alpha- and beta-receptor signals in cells expressing both receptor types. J Biol Chem 1992, 267:15635-15641.

31. Wennstrom S, Siegbahn A, Yokote K, Arvidsson AK, Heldin CH, Mori S, et al: Membrane ruffling and chemotaxis transduced by the PDGF betareceptor require the binding site for phosphatidylinositol $3^{\prime}$ kinase. Oncogene 1994, 9:651-660.

32. Ahmad A, Wang Z, Kong D, Ali R, Ali S, Banerjee S, et al: Platelet-derived growth factor-D contributes to aggressiveness of breast cancer cells by up-regulating Notch and NF-kappaB signaling pathways. Breast Cancer Res Treat 2011, 126:15-25.

33. Kang DW, Min dS: Platelet derived growth factor increases phospholipase D1 but not phospholipase D2 expression via NFkappaB signaling pathway and enhances invasion of breast cancer cells. Cancer Lett 2010, 294:125-133.

34. Ostman A: PDGF receptors-mediators of autocrine tumor growth and regulators of tumor vasculature and stroma. Cytokine Growth Factor Rev 2004, 15:275-286.

35. Ostman A, Heldin CH: PDGF receptors as targets in tumor treatment. Adv Cancer Res 2007, 97:247-274.

36. Faraone D, Aguzzi MS, Toietta G, Facchiano AM, Facchiano F, Magenta A, et al: Platelet-derived growth factor-receptor alpha strongly inhibits melanoma growth in vitro and in vivo. Neoplasia 2009, 11:732-742.

37. McCarty MF, Somcio RJ, Stoeltzing O, Wey J, Fan F, Liu W, et al: Overexpression of PDGF-BB decreases colorectal and pancreatic cancer growth by increasing tumor pericyte content. J Clin Invest 2007, 117:2114-2122.

38. Rosenkranz S, Kazlauskas A: Evidence for distinct signaling properties and biological responses induced by the PDGF receptor alpha and beta subtypes. Growth Factors 1999, 16:201-216.

39. Brazil DP, Hemmings BA: Ten years of protein kinase B signalling: a hard Akt to follow. Trends Biochem Sci 2001, 26:657-664.

40. Manning BD, Cantley LC: AKT/PKB signaling: navigating downstream. Cell 2007, 129:1261-1274.

41. Toker A, Yoeli-Lerner M: Akt signaling and cancer: surviving but not moving on. Cancer Res 2006, 66:3963-3966.

42. Huang F, Greer A, Hurlburt W, Han X, Hafezi R, Wittenberg GM, et al: The mechanisms of differential sensitivity to an insulin-like growth factor-1 receptor inhibitor (BMS-536924) and rationale for combining with EGFR/ HER2 inhibitors. Cancer Res 2009, 69:161-170.

43. Hou X, Huang F, Carboni JM, Flatten K, Asmann YW, Ten EC, et al: Drug efflux by breast cancer resistance protein is a mechanism of resistance to the benzimidazole insulin-like growth factor receptor/insulin receptor inhibitor, BMS-536924. Mol Cancer Ther 2011, 10:117-125.

44. Abraham J, Prajapati SI, Nishijo K, Schaffer BS, Taniguchi E, Kilcoyne A, et al: Evasion mechanisms to Igf1r inhibition in rhabdomyosarcoma. $\mathrm{Mol}$ Cancer Ther 2011, 10:697-707.

45. Campbell Cl, Thompson DE, Siwicky MD, Moorehead RA: Murine mammary tumor cells with a claudin-low genotype. Cancer Cell International 2011, 11:28.

46. Herschkowitz J, Simin K, Weigman VJ, Mikaelian I, Usary J, Hu Z, et al: Identification of conserved gene expression features between murine mammary carcinoma models and human breast tumors. Genome Biol 2007, 8:R76.

47. Prat A, Parker JS, Karginova O, Fan C, Livasy C, Herschkowitz Jl, et al: Phenotypic and molecular characterization of the claudin-low intrinsic subtype of breast cancer. Breast Cancer Res 2010, 12:R68.

\section{Pre-publication history}

The pre-publication history for this paper can be accessed here:

http://www.biomedcentral.com/1471-2407/11/480/prepub doi:10.1186/1471-2407-11-480

Cite this article as: Campbell and Moorehead: Mammary tumors that become independent of the type I insulin-like growth factor receptor express elevated levels of platelet-derived growth factor receptors. $B M C$ Cancer 2011 11:480.

\section{Submit your next manuscript to BioMed Central and take full advantage of:}

- Convenient online submission

- Thorough peer review

- No space constraints or color figure charges

- Immediate publication on acceptance

- Inclusion in PubMed, CAS, Scopus and Google Scholar

- Research which is freely available for redistribution

Submit your manuscript at www.biomedcentral.com/submit
Biomed Central 